\title{
Refining grain structure and porosity of an aluminium alloy with intensive melt shearing
}

Y. Zuo*, H. Li, M. Xia, B. Jiang, G.M. Scamans and Z. Fan

LiME (EPSRC Centre for Innovative Manufacturing in Liquid Metal Engineering)

BCAST

Brunel University

Uxbridge

Middlesex

UB8 3PH

UK

*Corresponding author:

Tel: +44 1895266411 Fax: +44 1895269758

\begin{abstract}
Intensive melt shearing was achieved using a twin-screw machine to condition an aluminium alloy prior to solidification. The results show that intensive melt shearing has a significant grain-refining effect. In addition, the intensive melt shearing reduces both the volume fraction and the size of porosity. It can reduce the density index from $10.50 \%$ to $2.87 \%$ and the average size of porosity in the samples solidified under partial vacuum from around $1 \mathrm{~mm}$ to $100 \mu \mathrm{m}$.
\end{abstract}

\section{Keywords}

Aluminium alloys, Intensive melt shearing, Grain refining, Porosity

\section{Acknowledgements}

The authors thank Mr. Phil Enright for helpful and very useful discussions on the use of the reduced pressure test (RPT). Financial support from the EPSRC and the Technology Strategy Board is also gratefully acknowledged. 
Grain refinement is important for improving mechanical properties, reducing the size of defects and increasing the resistance to hot tearing, especially when producing large, highly alloyed ingots [1], [2] and [3]. Al-Ti-B master alloy is a good grain refiner for aluminium alloys [4] and [5]; however, it also causes other problems associated with melt contamination and formation of particles which cannot be removed by heat treatment. The search for new and effective grain refiners and methods for grain refinement continues [2], [3], [6] and [7]. Fan and his co-workers [8] have found that after an intensive shearing the oxide films entrained within melts can be dispersed uniformly in the melt and can act as nucleation centres, and thereby reduce the grain size. This is therefore a feasible way to achieve grain refinement by intensive melt shearing alone without any addition of grain refiner. This means that a conventional grain refiner does not need to be added to the melt prior to casting. Generally, oxide films [1] and [9] in melts are considered to be detrimental as they can result in the formation of porosity and hot tearing. Porosity is highly detrimental, in terms of surface quality, mechanical properties and corrosion resistance [9], [10] and [11], and hot tearing can result in the scrapping of entire ingots. It is therefore necessary to eliminate or reduce the content of these casting defects. Based on the recently developed MCAST technology [6] and [7], in the present work intensive melt shearing was carried out on 7032 aluminium alloy to evaluate its possibility to transform oxide films from potential defects into potent grain refiners.

A commercial AA7032 aluminium alloy, Al-6.1Zn-1.9Mg-2.0Cu-0.20Cr-0.06Fe-0.04Si$0.02 \mathrm{Ti}$ (all wt.\%), was used in the present work. The measured liquidus temperature of AA7032 alloy is $636^{\circ} \mathrm{C}$. The alloy was melted at $720^{\circ} \mathrm{C}$ in a resistance furnace and then sheared in the MCAST unit under Ar protection. In the MCAST apparatus a pair of corotating and fully intermeshing screws are rotate inside a heated barrel with accurate temperature control. The temperature of the sheared melt was measured before further processing. The difference between the measured temperature of the sheared melt and the set point is less than $3^{\circ} \mathrm{C}$. After shearing at $500 \mathrm{rpm}$ for $1 \mathrm{~min}$, the melt was cast into a TP1 mould [12] to study the grain-refining effect of shearing, which provides a constant cooling rate around $3.5 \mathrm{~K} \mathrm{~s}^{-1}$ for aluminium alloys. The reduced pressure test (RPT) [9] and [11] was used to evaluate porosity levels in the alloy. Both sheared and non-sheared melts were poured into two thin-walled steel moulds to be solidified either in air at atmospheric pressure or under a partial vacuum ( $80 \mathrm{mbar}$ ). The density of the cast samples was measured using a 1610 LC balance and the density index Di, which indicates the porosity content level [9] and [11], was then calculated. The density index Di is defined as: 
$\mathrm{Di}=\frac{\mathrm{Da}-\mathrm{Dv}}{\mathrm{Da}}$,

where Da is the density of sample solidified in air and Dv is the density of sample solidified under partial vacuum.

The hydrogen concentration in the melt was also directly measured in a ceramic crucible with an inner diameter of $125 \mathrm{~mm}$ and a height of $275 \mathrm{~mm}$ using a FOSECO ALSPEK H. The liquid AA7032 alloy was sheared in an MCAST unit at $660^{\circ} \mathrm{C}$ for $60 \mathrm{~s}$ and collected in a ceramic crucible. The sheared melt was isothermally held at $660^{\circ} \mathrm{C}$ in a resistance furnace and then the hydrogen concentration was directly measured within $30 \mathrm{~min}$.

The samples were cut, ground and polished using a standard metallographic technique. The TP1 samples were anodized using $2 \% \mathrm{HBF}_{4}$ and the RPT samples were etched using Keller's reagent for optical microscopy.

In order to study the grain-refining effect of intensive melt shearing, TP1 samples both with and without intensive melt shearing were cast. The microstructure of TP1 samples is shown in Figure 1. Figure 1a shows the equiaxed dendritic microstructure of the conventionally processed TP1 sample cast at $660^{\circ} \mathrm{C}$. Figure $1 \mathrm{~b}$ shows that after shearing at the same temperature, the microstructure becomes finer and more uniform.

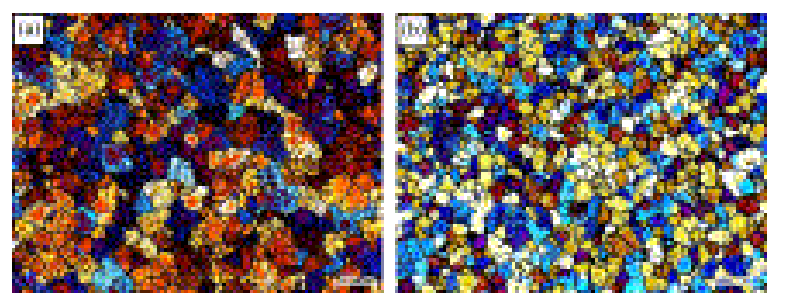

Figure 1: Microstructure of 7032 alloy cast in a TP1 mould at $660^{\circ} \mathrm{C}-$ (a) without shearing - (b) with shearing

The correlation between average grain size of TP1 samples and the casting temperature is shown in Figure 2. In general, after shearing, the average grain size is smaller. With increasing casting temperature, the average grain size of the TP1 samples without melt shearing increases quickly, while the average grain size of the sheared samples does not change significantly and is less variable. Intensive melt shearing can achieve significant grain refinement and the difference between the sheared and non-sheared samples increases at higher temperatures. However, unfortunately, because of the present 
temperature limitation of the melt conditioning machine, the maximum shearing temperature available was $660^{\circ} \mathrm{C}$.

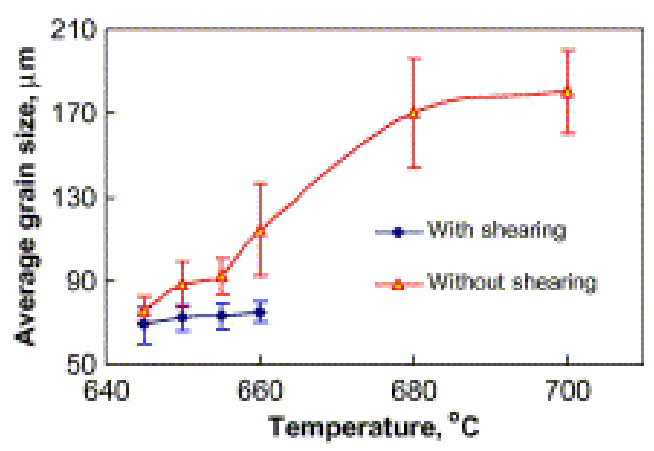

Figure 2: Variation of average grain size as a function of casting temperature for TP1 samples with and without melt shearing

The effect of intensive melt shearing on porosity was also studied. It is difficult to identify the porosity in the samples cast at atmospheric pressure because it is usually very fine and the content is very low, especially when casting clean melt with a low hydrogen concentration. At reduced pressure, porosity is enlarged and it is possible to see a clear difference between the sheared and non-sheared samples. The measured densities and calculated Di of AA7032 alloy are shown in Figure 3. After shearing, the Da increases slightly; Dv increases significantly and the density index Di decreases remarkably from $10.50 \%$ to $2.87 \%$, reflecting that the porosity content in the sheared sample is much lower than that of the non-sheared sample. This was also confirmed in LM24 cast aluminium alloy, in which the Di was reduced from $12.41 \%$ to $2.96 \%$ by intensive melt shearing.

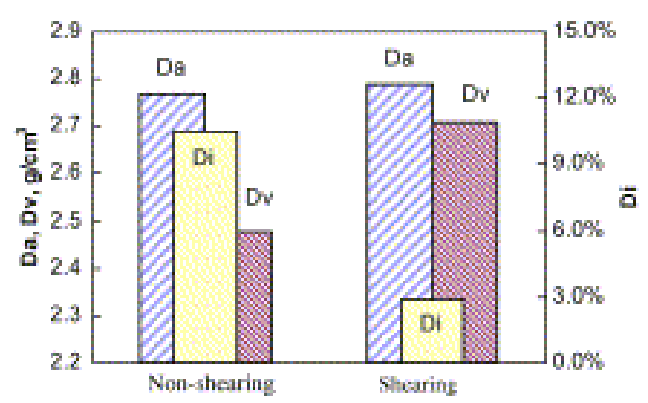

Figure 3: Comparison of the densities and density index of 7032 aluminium alloy with and without melt shearing

After measuring the densities, the samples were cut and then ground and polished for optical metallographic examination of the morphology of the porosity. Figure 4 shows 
the longitudinal cross-section of the samples solidified under partial vacuum ( 80 mbar) with and without melt shearing. For the non-sheared sample, Figure 4a shows large pores inside the sample and a convex top surface. In contrast, the sheared sample, Figure $4 b$, has a concave top surface and is much less porous. The close-up views are also shown in Figure 4 as indicated by the arrows. There are both large round pores (about $1 \mathrm{~mm}$ in size) and shrinkage porosities with irregular shape between dendrites in the non-sheared sample. In contrast to this, for the sample with intensive melt shearing, the porosity is around $100 \mu \mathrm{m}$ in diameter, which is much smaller than that of nonsheared one.

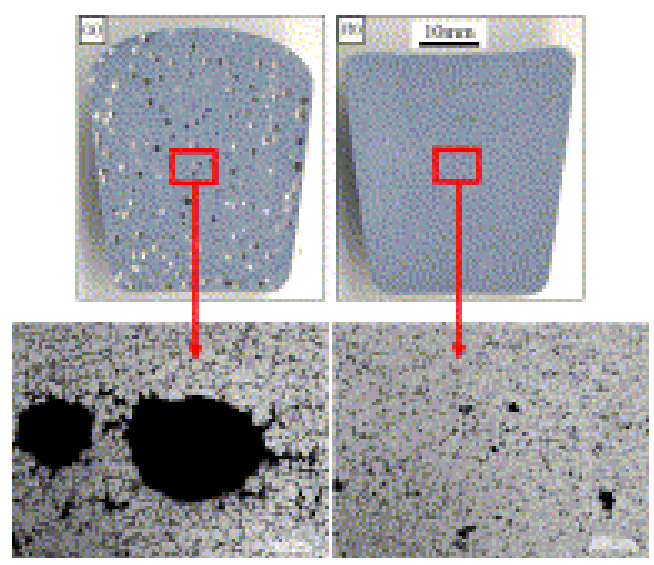

Figure 4: Sectioned 7032 alloy samples solidified under partial vacuum (80mbar) - (a) without shearing - (b) with shearing

The hydrogen concentration in liquid AA7032 alloy was also measured using an ALSPEK $\mathrm{H}$ both before and after shearing to understand the effect of intensive shearing on porosity. Table 1 shows the measured hydrogen concentration in the liquid alloy. The hydrogen concentration in the melt is reduced from $0.2 \mathrm{ml} / 100 \mathrm{~g}$ to $0.11 \mathrm{ml} / 100 \mathrm{~g}$ by intensive melt shearing.

Table 1: Hydrogen concentration in liquid AA7032 alloy

\begin{tabular}{|l|l|}
\hline Conditions & Hydrogen concentration $(\mathbf{m l} / \mathbf{1 0 0} \mathbf{g})$ \\
\hline Non-shearing & 0.2 \\
\hline Shearing & 0.11 \\
\hline
\end{tabular}

Intensive melt shearing can not only achieve the grain refinement but also reduce both the content and the size of the porosity. It is important to understand how this is achieved by the use of high-shear melt conditioning. 
The surface of liquid aluminium is always oxidized in normal atmospheres. There are two sides of the oxide film: one is the dry side, which is exposed to air; the other is the wet side, which is in direct contact with the alloy melt. If the surface is disrupted during melting, melt handling or pouring, the surface film is folded over to form a bifilm and becomes entrained in the melt [1]. Usually, entrained oxides and bifilms are found as clusters or films that are distributed non-uniformly in the melt. These oxide films can be nucleation sites to some extent, but they cannot refine grain very much because of the small number of oxide films and their poor wettability. However, the cluster or the film can be broken up and well dispersed as individual oxide particles with a fine size and a narrow size distribution by intensive melt shearing [8]. Based on the free growth model [13], the uniformity of the particles plays a very important role in grain refining; and uniform and well-dispersed nucleating substrates with a narrow size distribution are highly beneficial for grain refinement. The existence of good kinetic conditions in the liquid metal during intensive melt shearing could help to improve the wettability between the liquid alloy and the dispersed oxide particle, and as a consequence enhance nucleating activity. It has been confirmed in related work that the oxide particles can act as nucleation sites [8]. The results of the present work are consistent with uniform and well-dispersed oxide particles contributing greatly to grain refinement by intensive melt shearing.

With a certain content of gas in the melt, there are two main factors that affect porosity nucleation: (i) the presence of solid foreign substrates, e.g., oxide bifilms; and (ii) the wettability of the surfaces. A well wetted surface can be a location for nucleation of aluminium alloy, whereas a poorly wetted surface can act as a nucleation centre not for aluminium alloy but for the porosity. Bifilms can provide a poorly wetted surface inside the bifilm for porosity nucleation particularly if there is a negative pressure during solidification. This is why there are so many large pores in the conventional RPT sample. However, oxide bifilms can be transformed into well-dispersed individual particles by intensive melt shearing. The poorly wetted surface inside the bifilm is therefore eliminated and the wettability of the particles is supposed to be improved. In consequence, it is difficult for the particles to act as nucleation sites for the porosities. The number of nucleation centres for the porosity is therefore reduced.

It is also found that intensive melt shearing has a significant degassing effect on aluminium alloys. During the shearing process, the twin-screw machine was protected by Ar. Before pouring the melt in the machine, the cavity between the twin-screw and the inner surface of the barrels is filled with Ar. When pouring the melt, it will drive Ar out 
because of the density difference and fine Ar bubbles will be formed in the liquid metal under intensive melt shearing. The hydrogen in the melt diffuses to the bubbles because the hydrogen partial pressure is lower in the bubbles than in the melt. During shearing, some of the bubbles will exit and new bubbles will be introduced via absorption of $\mathrm{Ar}$ near the top surface into the melt. These two processes are continuously working and will be in a balance. When the bubbles exit they will take the hydrogen out as well. This is the main reason why intensive melt shearing can degas the melt.

The elimination of bifilms, the improvement of the wettability of the dispersed oxide particles and the reduced hydrogen content after intensive melt shearing result in much lower porosity compared to non-conditioned samples.

In summary, intensive melt shearing was achieved in a MCAST unit and was used to condition AA7032 alloy prior to solidification. It was found that intensive melt shearing had a significant grain-refining effect on AA7032 aluminium alloy. The samples with intensive melt shearing showed much finer and more uniform equiaxed grains. In addition, the intensive melt shearing reduced both the volume fraction and the size of porosity. It reduced the density index ( $\mathrm{Di}$ ) from $10.50 \%$ to $2.87 \%$ and the average size of porosity in the sample solidified under partial vacuum from around $1 \mathrm{~mm}$ to $100 \mu \mathrm{m}$.

\section{References}

1. J. Campbell, Castings (second ed.), Elsevier, Amsterdam (2003).

2. Y. Zuo, J. Cui, J. Dong and F. Yu, Mater. Sci. Eng. A 408 (2005), p. 176.

3. Y. Zuo, J. Cui, Z. Zhao, H. Zhang and K. Qin, Mater. Sci. Eng. A 406 (2005), p. 286.

4. P.S. Mohanty and J.E. Gruzleski, Acta Mater. 43 (1995), p. 2001.

5. B.S. Murty, S.A. Kori and M. Chakraborty, Int. Mater. Rev. 47 (2002), p. 3.

6. Z. Fan, M. Xia, H. Zhang, G. Liu, J.B. Patel, Z. Bian, I. Bayandorian, Y. Wang, H.T. Li and G.M. Scamans, Int. J. Cast Met. Res. 22 (2009), p. 103.

7. Z. Fan, Y. Wang, Z.F. Zhang, M. Xia, H.T. Li, J. Xu, L. Granasy and G.M. Scamans, Int. J. Cast Met. Res. 22 (2009), p. 318.

8. Z. Fan, Y. Wang, M. Xia and S. Arumuganathar, Acta Mater. 57 (2009), p. 4891.

9. S. Fox and J. Campbell, Scripta Mater. 43 (2000), p. 881.

10. ASM Handbook, Casting, vol. 15, 2008, p. 185.

11. M. Samuel and F.H. Samuel, Metall. Trans. A 24 (1993), p. 1857. 
12. Standard test procedure for aluminium alloy grain refiners (TP-1), The Aluminium Association, Washington, DC, 1990.

13. A.L. Greer, A.M. Bunn, A. Tronche, P.V. Evans and D.J. Bristow, Acta Mater. 48 (2000), p. 2823. 